\title{
Platelet-derived Growth Factor in Idiopathic Pulmonary Fibrosis
}

\author{
Harry N. Antoniades, ${ }^{\star *}$ Martin A. Bravo, ${ }^{\ddagger 5}$ Rafael E. Avila, ${ }^{\ddagger}$ Theofanis Galanopoulos, ${ }^{*}$ Janine Neville-Golden, ${ }^{*}$ \\ Marius Maxwell, ${ }^{\star}$ and Moises Selman \\ ${ }^{*}$ The Center for Blood Research and ${ }^{\ddagger}$ Departments of Cancer Biology and Nutrition, Harvard School of Public Health, Boston, \\ Massachusetts 02115; and ${ }^{\S}$ Division de Investigacion, Instituto Nacional de Enfermedades Respiratorias, Mexico City, Mexico
}

\begin{abstract}
Fibrosis is a complex process involving an inflammatory reaction, fibroblast proliferation, and abnormal accumulation of interstitial collagens. Mononuclear cells are usually present in lung fibrosis. Activated monocytes and macrophages in culture have been shown to produce several growth factors including platelet-derived growth factor (PDGF). PDGF is a potent mitogen and chemoattractant for fibroblasts and smooth muscle cells and a stimulator of collagen synthesis. We have studied the expression of c-sis/PDGF-2 mRNA in lung tissues derived from five patients with idiopathic pulmonary fibrosis (IPF) and from four control individuals without IPF. Northern blot analysis of specimens obtained from four patients with IPF revealed the expression of the c-sis/PDGF-2 protooncogene. A control lung tissue without IPF did not express the c-sis protooncogene. In situ hybridization extended these studies demonstrating the expression of the c-sis mRNA in the five specimens with IPF but not in the four control specimens without IPF. The expression of c-sis mRNA was localized primarily in the epithelial cells. Invading alveolar macrophages also expressed c-sis mRNA. The expression of c-sis mRNA was accompanied by the expression of PDGF-like proteins in lung specimens with IPF but not in control lung specimens. These findings demonstrate the in vivo expression of the c-sis/ PDGF-2 protooncogene and the production of PDGF-like proteins in the epithelial cells and macrophages of the fibrotic tissue. This localized and sustained production of PDGF-like mitogen may constitute an important contributing factor in the abnormal fibroblast proliferation and collagen production, events associated with pulmonary fibrosis. (J. Clin. Invest. 1990. 86:1055-1064.) Key words: PDGF • pulmonary fibrosis • interstitial lung disease $\bullet$ alveolar macrophages • cuboidal epithelium • interstitial collagen
\end{abstract}

\section{Introduction}

The interstitial lung diseases (ILD) ${ }^{1}$ are a heterogeneous group of diffuse inflammatory disorders that affect the pulmonary parenchyma (1-3). Idiopathic pulmonary fibrosis (IPF) is one

Address reprint requests to Prof. Harry N. Antoniades, The Center for Blood Research, 800 Huntington Ave., Boston, MA 02115. 1990.

Received for publication 15 May 1989 and in revised form 4 June

1. Abbreviations used in this paper: ILD, interstitial lung disease; IPF, idiopathic pulmonary fibrosis; PDGF, platelet-derived growth factor.

J. Clin. Invest.

(c) The American Society for Clinical Investigation, Inc.

$0021-9738 / 90 / 10 / 1055 / 10 \$ 2.00$

Volume 86, October 1990, 1055-1064 of the major ILDs of unknown origin. It is characterized by an increase in the number of inflammatory cells and a progressive alteration of the alveolo-capillary units by a fibrotic process. This process consists of an increase in fibroblast population (2, 3 ), and an excessive accumulation of interstitial collagens (4), which results in disruption of the gas exchange units causing progressive respiratory failure.

The processes mediating the proliferation of fibroblasts and increased collagen synthesis within the alveolar structures are not completely understood. In vitro studies have demonstrated that cultured alveolar macrophages obtained from patients with interstitial lung fibrosis release several growth factors $(5,6)$ including platelet-derived growth factor (PDGF) $(7$, 8). PDGF is a potent mitogen and chemoattractant for fibroblasts and smooth muscle cells and a stimulator of collagen synthesis by fibroblasts. It is normally transported in blood, stored in the alpha-granules of platelets. Human PDGF contains two polypeptide chains (PDGF-1 and PDGF-2) linked together by disulfide bonds (9). The PDGF-2, or PDGF-B, chain is encoded by the c-sis/protooncogene localized in chromosome 22, and the PDGF-1, or PDGF-A, chain is encoded by a gene localized in chromosome 7 (for review see reference 10). Activated monocytes and macrophages were shown to express the c-sis/PDGF-2 protooncogene and to synthesize and secrete PDGF-like mitogen $(7,8,11)$. Monocytes/macrophages are invariably increased in ILD, and it is possible that production of PDGF by these cells contributes to the progression of fibrosis and interstitial collagen accumulation. Support for this possibility has been provided by studies demonstrating that alveolar macrophages obtained from IPF patients express the c-sis/PDGF-2 gene and release PDGF-like mitogen (12). The present studies provide the first direct evidence for the expression of the c-sis protooncogene by human lung tissue obtained from patients with IPF. In situ hybridization has localized the c-sis mRNA both in macrophages and epithelial cells of the fibrotic tissue. Production of PDGF-like proteins was also localized in the macrophages and epithelial cells of patients with IPF but not in normal lung tissue. These studies suggest the possibility that the production of PDGF-like mitogen by epithelial cells and macrophages in lung tissue may be part of the mechanisms contributing to fibrosis and increased collagen deposition, both characteristics of human pulmonary fibrosis.

\section{Methods}

Tissue collection. Pulmonary specimens from five patients with IPF were collected by open lung biopsy. The patients were hospitalized in the National Institute of Respiratory Diseases, Mexico City, Mexico. They exhibited a typical clinical, radiographic, and respiratory functional picture, characterized by a progressive dyspnea, diffuse reticulonodular pattern on chest $\mathrm{x}$ ray, and a restrictive ventilatory defect with hypoxemia at rest that worsened with exercise. The definitive diagnosis was made by the morphological study of tissue samples ob- 
tained through open lung biopsy. Biopsies were performed after careful evaluation by the local medical/surgical committee for confirmation of diagnosis and for aiding the course of treatment. Control lung specimens were obtained from individuals undergoing lobectomy or wedge resection for removal of a primary lung tumor. The tissue sections used in these studies were free of pathologic evidence for malignancy.

In the present studies, we examined five lung specimens from patients with IPF and four control lung specimens without IPF. For Northern blot analysis the tissues were immediately snap frozen in liquid nitrogen before being stored in a $-80^{\circ} \mathrm{C}$ freezer. For in situ hybridization and immunocytochemistry, tissue specimens were processed as described below.

Northern blot analysis. Fragments of tissue were immediately placed in ice-cold $4 \mathrm{M}$ guanidinium isothiocyanate (Fluka AG, Buchs, Switzerland) before being homogenized by a polytron (setting 6 for 45-60 s). After being centrifuged for $2 \mathrm{~min}$ at $1,000 \mathrm{rpm}$, the supernatant fluid was carefully layered on a $5.7 \mathrm{M}$ cesium chloride cushion and centrifuged (Beckman Instruments, Inc., Fullerton, CA) in an SW 50.1 rotor at $35,000 \mathrm{rpm}, 20^{\circ} \mathrm{C}$ for $18 \mathrm{~h}$. Total RNA was then extracted by standard ethanol precipitation after phenol extraction. Aliquots of RNA ranging from 8 to $25 \mu \mathrm{g}$ were heated at $95^{\circ} \mathrm{C}$ for $2 \mathrm{~min}$ in a solution containing $50 \%$ formamide, $6 \%$ formaldehyde, and running buffer ( $20 \mathrm{mM}$ MOPS, pH 7.0, containing $5 \mathrm{mM}$ sodium acetate, 1 mM EDTA). The samples were electrophoresed at $35 \mathrm{~V}$ overnight on $1 \%$ agarose gels containing $6 \%$ formaldehyde and running buffer.

The RNA was transferred to Nytran nylon membranes (Schleicher \& Schuell, Inc., Keene, NH), using $10 \times$ SSC transfer buffer, and baked at $80^{\circ} \mathrm{C}$ for $1 \mathrm{~h}$ in a vacuum oven. The membranes were then hybridized at $42^{\circ} \mathrm{C}$ for $16 \mathrm{~h}$ with $1 \times 10^{6} \mathrm{cpm} / \mathrm{ml}$ of random-primer labeled (Amersham Corp., Arlington Heights, IL) cDNA probe in a solution containing 50\% formamide (Kodak Laboratory and Specialty Chemicals, Rochester, NY), $0.1 \%$ SDS, $5 \times$ SSPE, $5 \times$ Denhardt's mixture, and $200 \mu \mathrm{g} / \mathrm{ml}$ salmon sperm DNA (Sigma Chemical Co., St. Louis, MO). After washing at $65^{\circ} \mathrm{C}$ with $0.1 \times \mathrm{SSC}$, the membranes were subjected to autoradiography at $-70^{\circ} \mathrm{C}$ using intensifier screens. Normalization of RNA loading was achieved by subsequent hybridization of the membranes with the cDNA encoding $\beta$-actin. Positive-control RNA derived from a human glioblastoma cell line (A172), and negative-control RNA derived from a human lung fibroblast cell line (MRC-5).

The cDNA probes for these studies include c-sis/PDGF-2 (13), PDGF-1 (14), and $\beta$-actin (15).

In situ hybridization. Fresh tissue was cut into $2-\mathrm{mm}$ sections and immersed in ice-cold $4 \%$ paraformaldehyde for $2-8 \mathrm{~h}$ and then was allowed to sink in $30 \%$ sucrose/PBS overnight at $4^{\circ} \mathrm{C}$ to decrease freezing artifacts. The fixed tissues were then embedded in O.C.T. (Miles Laboratories, Inc., Naperville, IL) for cryostat serial sectioning $(8 \mu \mathrm{m})\left(30\right.$ sections per tissue) and in situ hybridization utilizing ${ }^{35} \mathrm{~S}-$ labeled CRNA probes was performed according to the method of Höffler et al. (16). The specificity of the cRNA probe for c-sis for in situ hybridization was controlled by Northern blot analysis and by hybridization of serial sections with noncomplementary RNA probes. Triplicate sections from each tissue were hybridized with either complementary antisense or noncomplementary sense probes and were developed at weekly intervals for over a period of $3 \mathrm{wk}$.

In situ hybridization combined with immunocytochemistry. To identify the cells expressing the c-sis/PDGF-2 protooncogene, we stained the tissues with markers specific for epithelial cells and macrophages after hybridization, and then counterstained with hematoxylin. For this combined step the dextran sulfate was deleted from the hybridization buffer to avoid background staining during immunocytochemistry. For epithelial cells, the tissue was stained with a polyclonal antibody to bovine antikeratin (Sigma Chemical Co.), and for monocytes/macrophages with the HAM 56 monoclonal antibody which also reacts with capillary endothelial cells (17). For the staining studies, after hybridization the tissues were washed with PBS, endogenous peroxidase activity was suppressed with $0.3 \% \mathrm{H}_{2} \mathrm{O}_{2}$ in methanol, and reacted with the appropriate antibody using the Vectastain $\mathrm{ABC}$ kit
(Vector Laboratories, Inc., Burlingame, CA). The tissues were then dehydrated and dipped in NT-B2 emulsion (Kodak Laboratory and Specialty Chemicals), and processed as described.

In situ hybridization combined with immunostaining for PDGFlike proteins. For the detection of PDGF-like proteins in lung tissue from patients with IPF, in situ hybridization was combined with staining with rabbit polyclonal PDGF antisera raised against pure human PDGF (10). These antisera recognize the PDGF heterodimer and both the PDGF-1 and PDGF-2 homodimers. The procedures for this study are identical to those described above for the combined steps of in situ hybridization and immunocytochemistry. The specificity of the reaction with the PDGF antisera was tested by control studies based on the preincubation of the antisera with excess $(50 \mu \mathrm{g})$ of purified human PDGF or recombinant c-sis/PDGF-2 homodimer (Institute of Molecular Biology, Boston, MA).

\section{Results}

Expression of the c-sis/PDGF-2 protooncogene by lung tissue of patients with IPF. RNA samples derived from lung tissue of a patient with IPF and from control lung tissue without IPF were subjected to Northern blot analysis. As shown in Fig. $1 \mathrm{~A}$, the c-sis/PDGF-2 protooncogene was expressed by the lung tissue of a patient with IPF and by a positive control glioblastoma cell line, A-172. Lung tissue without IPF did not express the c-sis protooncogene. In this study $25 \mu \mathrm{g}$ of RNA was applied in each lane. The RNA blots were rehybridized with a $\beta$-actin probe to establish that differences in c-sis protooncogene expression were not due to differences in the amount of RNA used in the individual samples. In a separate study shown in Fig. $1 \mathrm{~B}$, we examined the expression of the c-sis protooncogene in three additional specimens of lung tissue with IPF (lanes 2-4). The small size of the tissue specimens available for this study yielded smaller amounts of RNA for Northern blot analysis. However, all of these specimens ex-

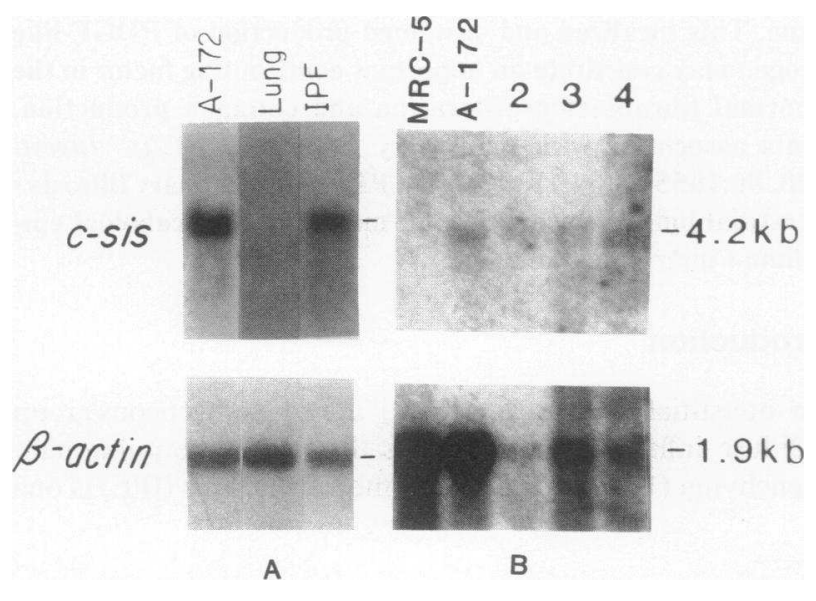

Figure 1. Northern blot analysis for the expression of the c-sis/ PDGF-2 protooncogene in human lung tissue of a patient with IPF and a human control lung tissue without IPF. Positive control for c-sis expression includes RNA from a human glioblastoma cell line (A-172), and negative control from the human MRC-5 fibroblast cell line. In blot $1 A$, the amount of RNA per sample is $25 \mu \mathrm{g}$. In blot 1 $B$, RNA was extracted from three additional lung specimens of patients with IPF (lanes 2-4). Total RNA extracted and applied in this blot is as follows: positive control, glioblastoma cell line A-172, 25 $\mu \mathrm{g}$; negative control MRC-5 fibroblast cell line, $25 \mu \mathrm{g}$; lane 2, $8 \mu \mathrm{g}$; lane $3,10 \mu \mathrm{g}$; lane $4,10 \mu \mathrm{g}$. 

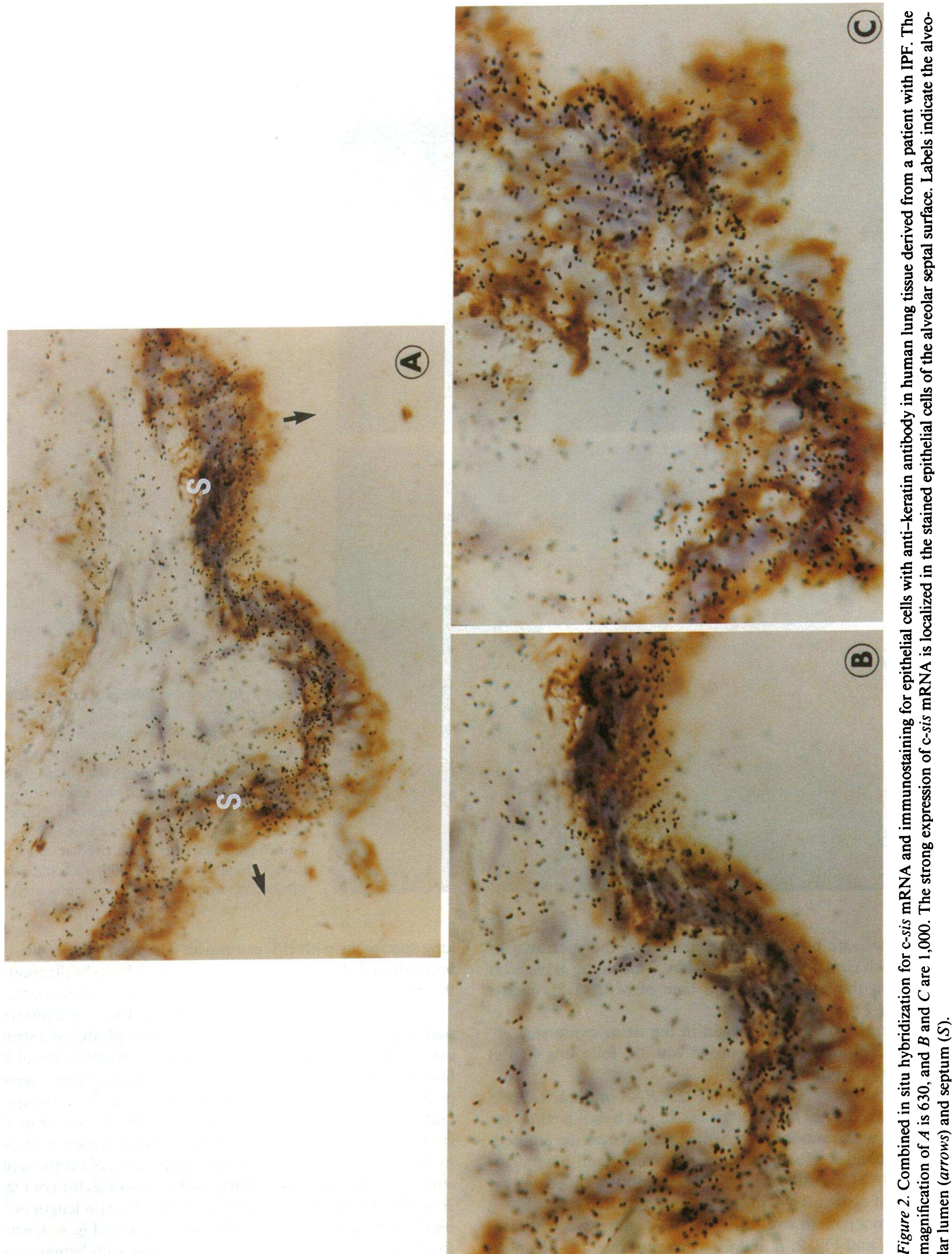

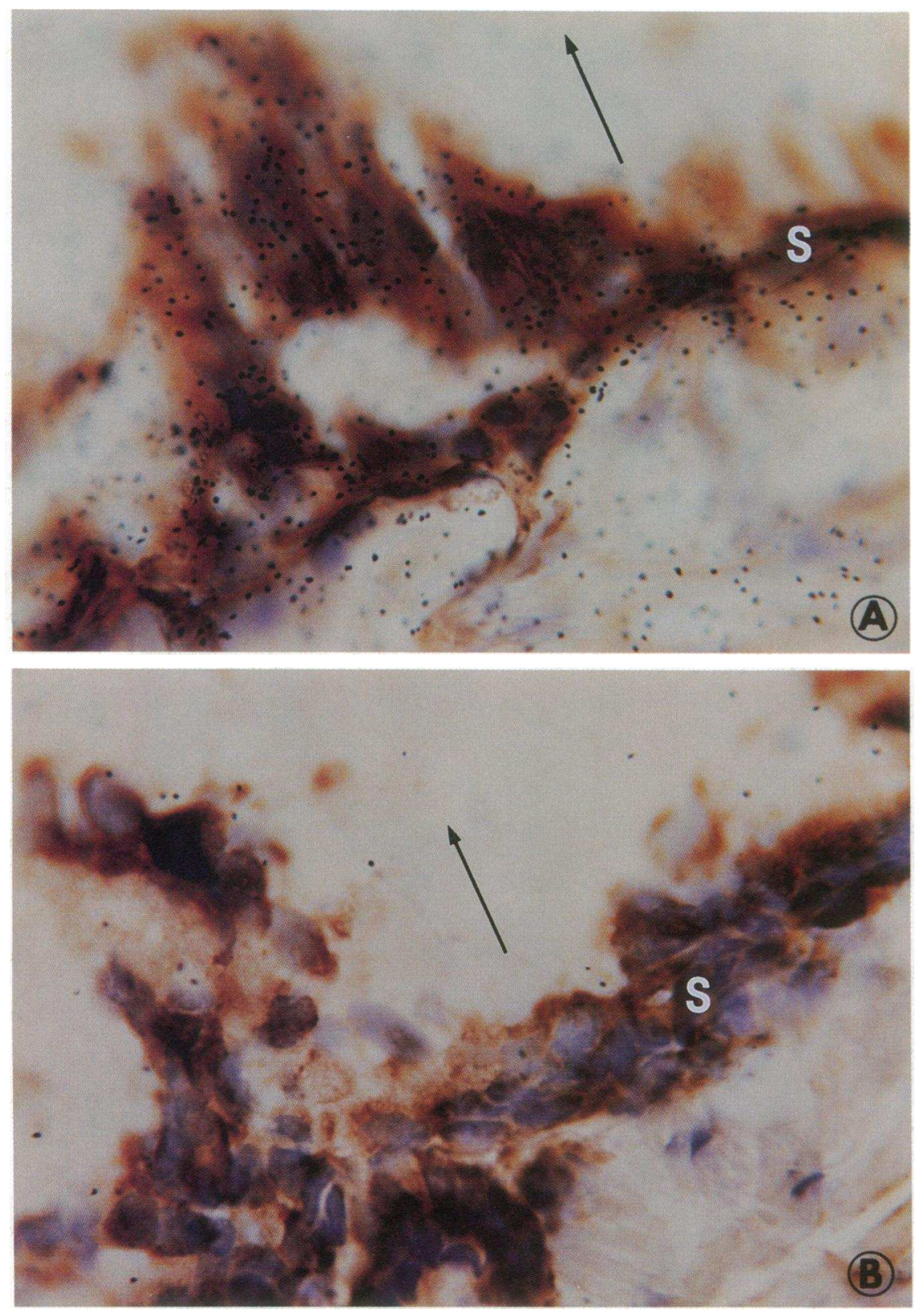

Figure 3. In situ hybridization for c-sis mRNA in lung sections of a patient using complementary $(A)$ or control noncomplementary "sense" $(B)$ RNA probes. Notice the strong expression of c-sis mRNA with the complementary probe $(A)$ and the lack of a significant expression with the noncomplementary "sense" probe. The expression was localized in the stained epithelial cells of the alveolar septal surface. Magnification, 1,000. Labels indicate the alveolar lumen (arrows) and septum $(S)$. pressed the c-sis protooncogene, including the specimen in lane 2 which contained $<8 \mu \mathrm{g}$ of RNA. There is no expression for c-sis in the negative control lane of MRC-5 fibroblasts containing $25 \mu \mathrm{g}$ of RNA.

To identify the cells of origin in the tissue expressing the c-sis protooncogene, we proceeded with the following studies using in situ hybridization.

Localization of the c-sis/PDGF-2 MRNA in epithelial cells and macrophages of IPF lung tissue. In situ hybridization was combined with immunocytochemistry using specific antibodies for epithelial cells (anti-keratin antibody) and for macrophages (HAM56 antibody). Fig. 2 demonstrates the strong expression of c-sis mRNA in the stained epithelial cells of lung tissue from a patient with IPF. Fig. $2 A$ represents a 630 magnification, and Fig. 2, $B$ and $C$, represents an expanded magnification of 1,000. The data shown in Fig. 2 are representative of the data obtained in the tissue sections derived from the five lung specimens with IPF examined. The specificity of the hybridization data shown in Fig. 2 was tested by hybridization of the fibrotic lung sections with control noncomplementary "sense" RNA probe for c-sis. As shown in Fig. $3 \mathrm{~A}$, hybridization with complementary "antisense" probe produced a strong expression of c-sis mRNA in the stained epithelial cells of the fibrotic tissue. Hybridization with noncomplementary "sense" probe did not produce a significant signal (Fig. 3 B). In Figs. 2 and $3 A$, the autoradiographic grains were localized in the stained epithelial cells of the alveolar septal surface as shown by light microscopy. The stained epithelial cells on the septal surface can be seen more clearly in the control section of Fig. 3 $B$, in the absence of distortion caused by the path length of ${ }^{35} \mathrm{~S}$ used for the labeling of the cRNA probe, and in Fig. $6 \mathrm{~A}$, where the epithelial cells were counterstained only with hematoxylin. In contrast to the results obtained in IPF tissues, the four normal lung tissues without IPF did not express c-sis mRNA. 

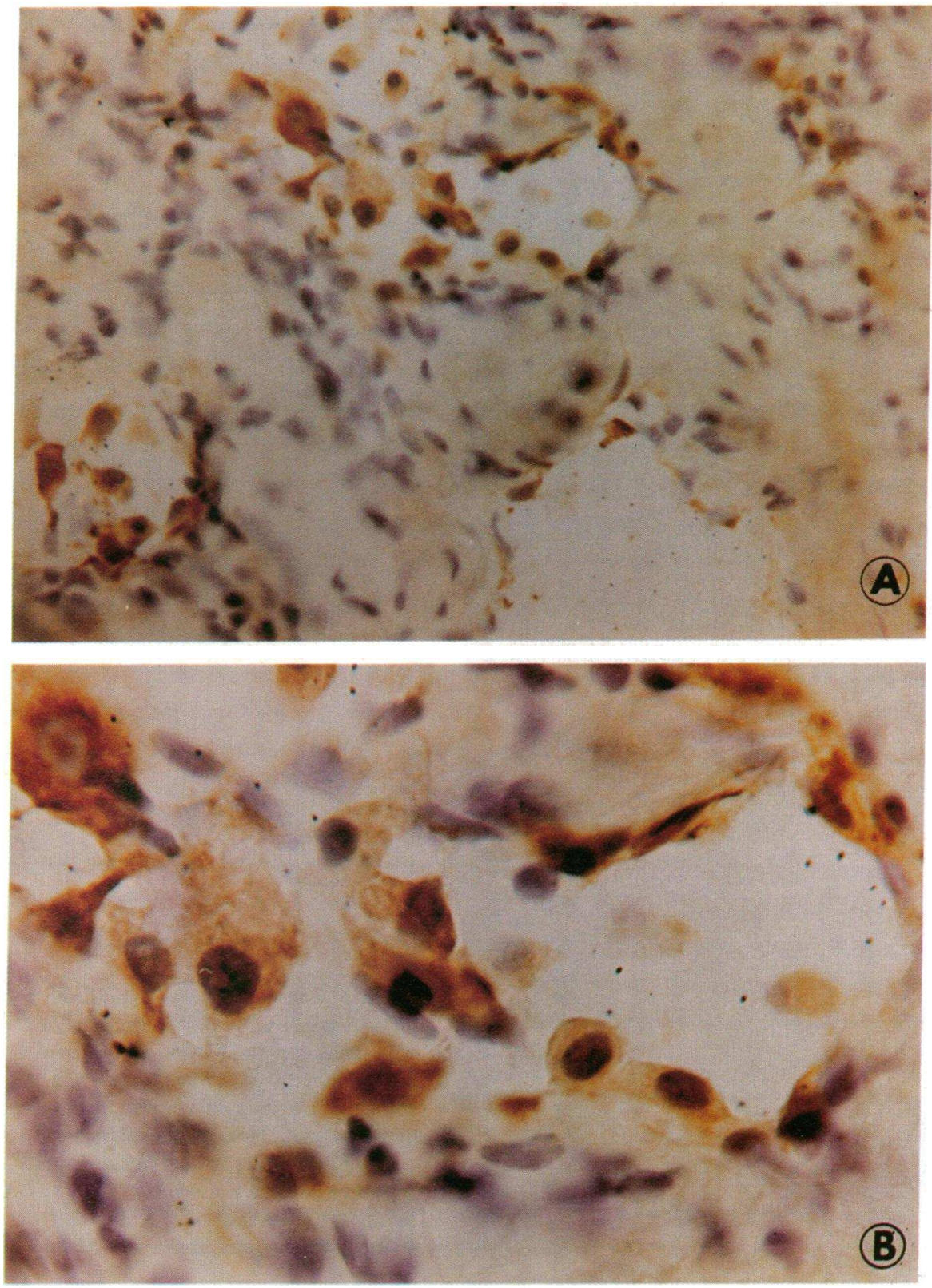

Figure 4. Combined in situ hybridization for c-sis mRNA and immunostaining for epithelial cells with anti-keratin antibody in control human lung tissue without IPF. The magnification in Fig. $4 A$ is 400 , and $B$ is 1,000 . Notice the lack of expression of c-sis mRNA in the control lung tissue without IPF.
As shown in Fig. 4, there is no evidence for c-sis mRNA expression in the stained epithelial cells of the control tissue without IPF.

Invading macrophages in IPF lung tissue also expressed c-sis mRNA. This is demonstrated in Fig. 5, which represents a combined in situ hybridization for c-sis mRNA and immunostaining for macrophages. A weak expression of c-sis mRNA was also observed in the capillary endothelial cells that were stained with the HAM56 antibody (Fig. $5 \mathrm{~B}$ ). The expression of c-sis mRNA in macrophages is further demonstrated in Fig. 6. A strong expression of c-sis mRNA can be seen in both epithelial cells and stained alveolar macrophages (Fig. $6 \mathrm{~A}$ ). Clusters of macrophages infiltrating the fibrotic tissue also expressed c-sis mRNA (Fig. 6, $B$ and $C$ ). Control hybridization with noncomplementary probe did not produce a significant signal in the stained macrophages (Fig. $6 \mathrm{D}$ ). The in situ hybridization studies described above demonstrated the expression of c-sis mRNA in both epithelial cells and macrophages in IPF lung tissue. Capillary endothelial cells in these studies showed much less hybridization.

Detection of PDGF-like proteins in lung tissue of patients with IPF. The expression of c-sis mRNA in the lung tissue sections of patients with IPF was accompanied by the expression of PDGF-like proteins as shown by immunocytochemistry using specific PDGF antisera. In contrast, control nonfibrotic lung tissue did not express PDGF-like proteins. As shown in Fig. $7 \mathrm{~A}$, there is a strong expression of PDGF-like proteins in fibrotic tissue stained with PDGF antisera. The specificity of this immunostaining reaction was tested by neutralizing the PDGF antisera with excess purified human PDGF or recombinant c-sis/PDGF-2 homodimer. Fig. $7 \mathrm{~B}$ shows that there is no immunostaining when the PDGF antisera were preincubated with excess (50 ng) purified PDGF. Similar results were obtained when the PDGF antisera were preincu- 

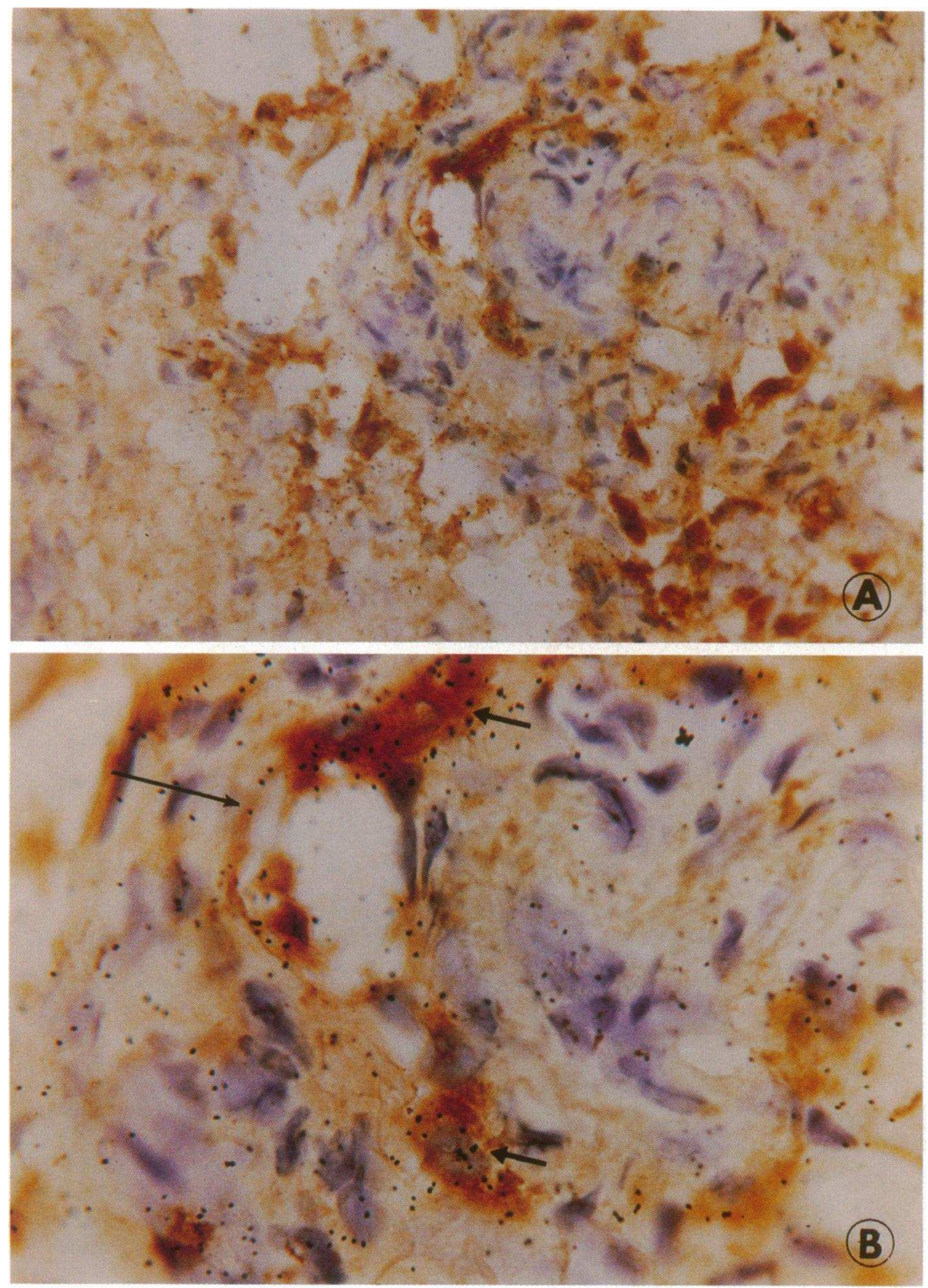

Figure 5. Combined in situ hybridization for c-sis mRNA and immunostaining for macrophages with HAM56 antibody in human lung tissue derived from a patient with IPF. The magnification in $A$ is 400 , and $B$ is 1,000 . Notice the expression of c-sis mRNA in the stained invading macrophages in the IPF tissue (short arrows). A weak expression is also evident in the stained capillary endothelial cells (long arrow). bated with excess recombinant PDGF (data submitted, not shown). Control nonfibrotic tissue did not express PDGF-like proteins when it was immunostained with the PDGF antisera (Fig. $7 \mathrm{C}$ ). This is consistent with the lack of expression of c-sis mRNA in the control nonfibrotic tissues. Fig. $7 D$ shows the focal co-expression of c-sis mRNA and PDGF-like proteins in a lung section of a patient with IPF. In this study we combined in situ hybridization for c-sis mRNA with immunostaining with PDGF antisera. As discussed by Höffler et al. (18), this combined procedure tends to enhance the intensity of the immunostaining and weaken the intensity of mRNA detection because of the added steps in this combined process.

\section{Discussion}

The present data provide the first direct evidence for the in vivo expression of the c-sis/PDGF-2 protooncogene in lung tissue derived from patients with idiopathic lung fibrosis (IPF). Lung tissue without IPF did not express the c-sis protooncogene. In situ hybridization studies demonstrated a strong expression of c-sis mRNA in epithelial cells and in macrophages and to a lesser extent in the capillary endothelial cells in the tissues from patients with IPF. Immunostaining with PDGFantisera detected PDGF-like proteins in lung tissue from patients with IPF but not in control nonfibrotic lung tissue. Furthermore, combined in situ hybridization and immunostaining with PDGF antisera demonstrated the co-expression of c-sis mRNA and PDGF-like proteins in the lung tissues of patients. The alveolar epithelial cells were the primary cells expressing c-sis mRNA and PDGF-like proteins. The in situ hybridization data for c-sis mRNA and the immunostaining data for PDGF-like proteins reported in this manuscript were uniform and reproducible in all sections derived from the five lung biopsies of patients. 


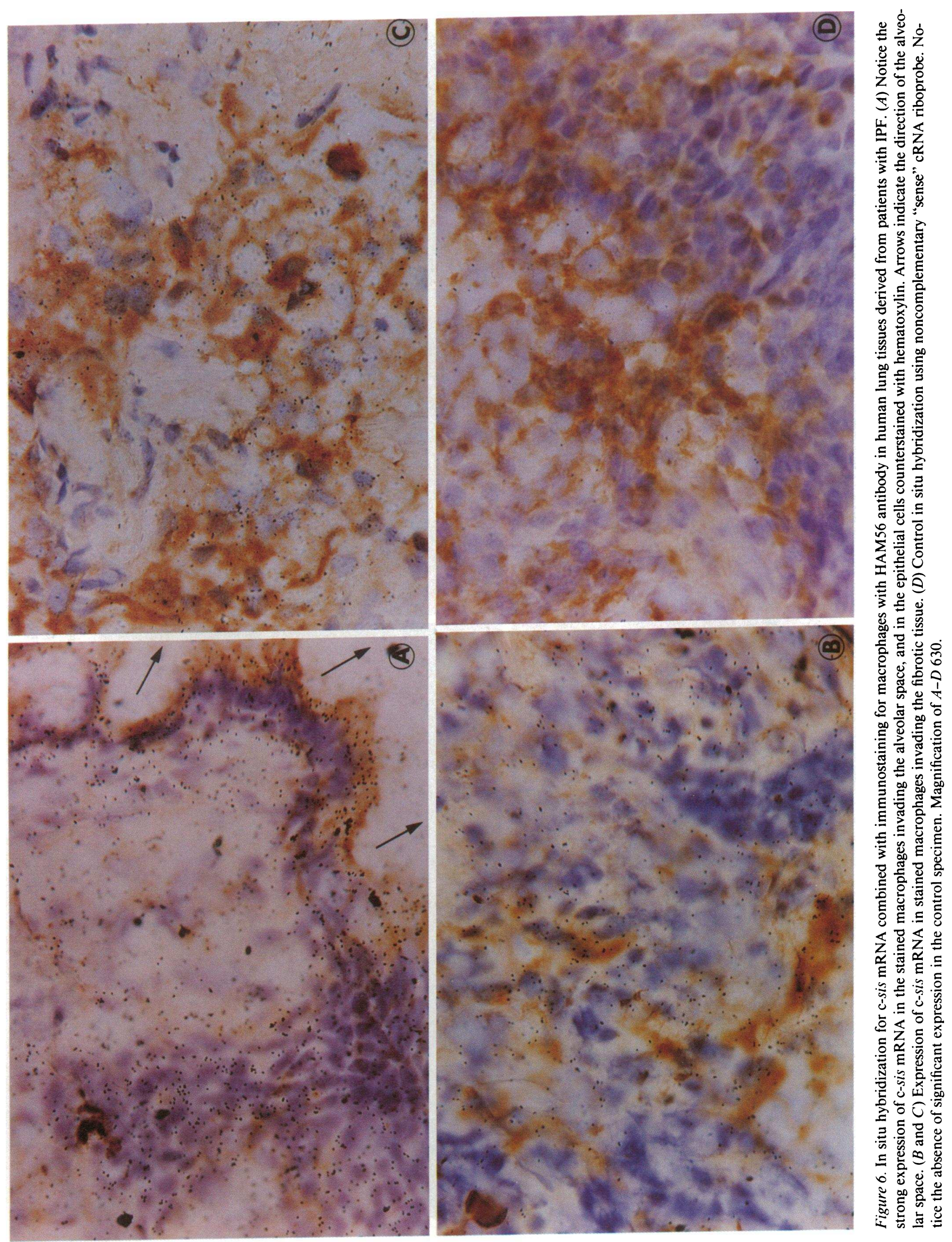



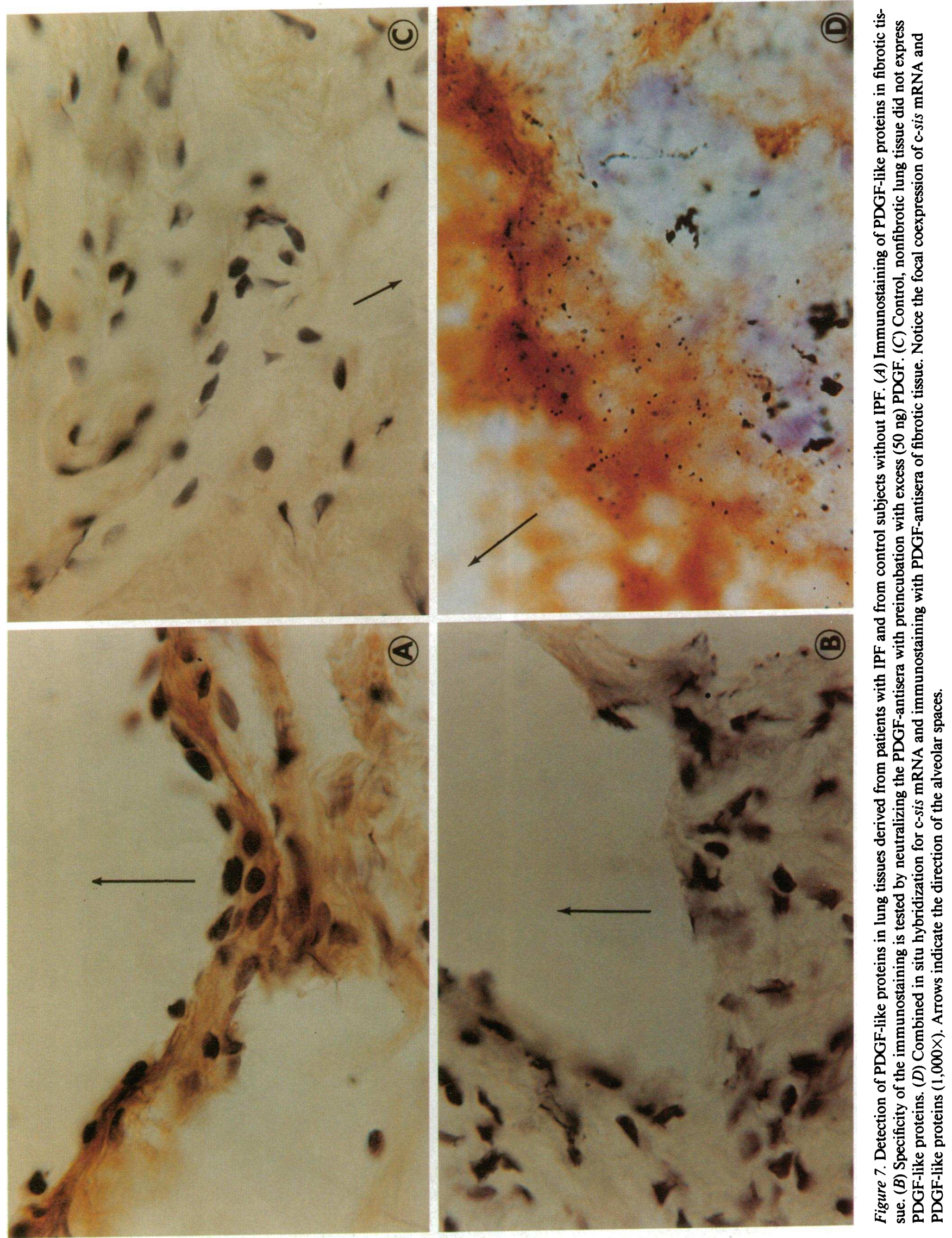
Previous studies have shown that cultured activated macrophages express the c-sis protooncogene and produce PDGFlike mitogen $(7,8,11)$. As shown by Martinet et al. (19), nonactivated alveolar macrophages obtained from normal humans by bronchoalveolar lavage released only small amounts of PDGF-like mitogen. In contrast, alveolar macrophages obtained from patients with IPF released much higher amounts (about fourfold) of PDGF-like mitogen. Our finding on the expression of the c-sis protooncogene by macrophages in lung tissue of patients with IPF are consistent with the observation on the spontaneous release of PDGF-like mitogen by alveolar macrophages obtained from patients with IPF (19). A spontaneous expression of c-sis mRNA by macrophages in diseased tissue does not appear to be a general phenomenon. For example, studies by Wilcox et al. (20) on the localization of PDGF mRNA in human atherosclerotic plaques failed to detect expression of c-sis mRNA in macrophages. Similarly, our in situ hybridization data of normal lung tissue failed to demonstrate the expression of c-sis mRNA. Mornex et al. (12) reported that nonactivated alveolar macrophages obtained by bronchoalveolar lavage from normal human smokers expressed c-sis transcripts as judged by Northern blot analysis. $\sim 20 \mu \mathrm{g}$ of total RNA extracted from the macrophages was used in that study. Our in situ hybridization in lung specimens of four control subjects without IPF that includes smokers did not demonstrate expression of c-sis mRNA. It is possible that a low expression of c-sis mRNA by their alveolar macrophages was not detectable by in situ hybridization and it was only apparent in an enriched RNA preparation obtained from macrophages (11). A weak expression of c-sis mRNA could be seen in capillary endothelial cells. This low expression in vivo is in contrast to high expression of c-sis mRNA seen in vitro in cultured endothelial cells $(21,22)$. However, our in vivo observation is consistent with the original finding of Barrett et al. (21) who reported a low expression of the c-sis gene in endothelial cells in vivo, compared to the high expression seen in vitro in cultured endothelial cells.

The studies described above demonstrated a strong expression of c-sis mRNA in epithelial cells in IPF tissue. Normally, epithelial cells do not express the c-sis protooncogene. For example, lung tissue without IPF did not express c-sis mRNA as judged by both Northern blot analysis and in situ hybridization. In contrast, cultured malignant epithelial cell lines derived from human patients with breast $(23,24)$, lung $(25)$, and prostatic (26) cancer were shown to express both PDGF genes and to secrete PDGF-like mitogen. Because epithelial cells do not display surface receptors to PDGF, it was suggested that secretion of PDGF-like mitogen by these cells serves for paracrine functions, such as development of fibrosis associated with human breast cancer $(23,24)$. The present study provides the first evidence for the spontaneous expression of the c-sis protooncogene by nonmalignant epithelial cells in lung biopsy specimen derived from patients with IPF.

In these studies the emphasis is on the expression of the c-sis/PDGF-2 mRNA. A weak expression of the gene encoding the PDGF-1 (A) polypeptide chain was detected during a 3-wk exposure in both non-IPF- and IPF-associated lung tissue, as judged by Northern blot analysis (data not shown). However, the expression of this gene was very weak, and it was not possible by in situ hybridization to localize the cells expressing the PDGF-1 mRNA in IPF or non-IPF lung tissue. Similarly, immunostaining with the PDGF antisera failed to detect the presence of PDGF-like proteins in non-IPF lung tissue (Fig. $7 C$ ).

Fibrosis and excessive collagen synthesis are events associated with IPF. The unregulated local production of PDGF may contribute to the expansion of connective tissue cells and collagen accumulation in lung parenchymal, because PDGF is a potent chemoattractant and mitogen for fibroblasts and smooth muscle cells (27-29) and a stimulator of collagen synthesis by fibroblasts. An increase in the number of fibroblasts within the alveolar structures, which has been demonstrated in both animals and humans with chronic interstitial lung disease $(30,31)$, is critical in the pathogenesis of lung fibrosis. Furthermore, PDGF can stimulate the production of collagenase (32) in fibroblasts, which may explain the progressive derangement in interstitial collagens at least in the initial phases of the disease. In this context, the presence of active collagenase within the lower respiratory tract can be responsible for ultrastructural alterations described in patients with IPF like the fragmentation and fraying of the collagen fibers in the lung interstitium (33).

The important new finding in these studies is the recognition of a strong expression of c-sis/PDGF-2 mRNA in the epithelial cells of lung tissue derived from patients with IPF. This "inappropriate" expression may be an important contributing factor in the development of fibrosis. The local constitutive production of PDGF-like mitogen by the epithelial cells, could serve for the paracrine recruitment and stimulation of target cells such as fibroblasts and smooth muscle cells, and to an exaggerated production and accumulation of interstitial collagens in patients with IPF.

The initial events leading to IPF are not known. Injury is considered to be among the causes of the disease. Recent studies have shown that acute injury in animals induces the reversible expression of the c-sis and PDGF receptor $b$ mRNAs in the epithelial cells of the injured tissue (Antoniades, H. N., et al., submitted for publication). Normal epithelial cells do not express c-sis and PDGF receptor mRNAs. The expression of the mRNAs in the epithelial cells occurred within $1 \mathrm{~d}$ of injury and it was suppressed by day five, which coincides with the time of reepithelialization of the injured tissue. These findings provide direct evidence that acute injury can induce a reversible expression of protooncogenes in the epithelium. It is conceivable that "chronic" injury can cause an irreversible, inappropriate gene expression, like the expression of the c-sis protooncogene in the lung epithelium of patients with IPF described in the present studies.

\section{Acknowledgments}

We express our thanks to Dr. Hubert J. Wolfe and Dr. Stephen P. Naber, Department of Pathology, Tufts University-New England Medical Center, for the advice and support in the in situ hybridization and immunocytochemistry studies. We express our thanks to Mrs. Amal Ghaly and Mrs. Deborah Wilkinson for the preparation of this manuscript.

Supported by funds from the National Institutes of Health grants CA30101, HL29583 (H. N. Antoniades), and the Council for Tobacco Research USA (H. N. Antoniades). Dr. M. Bravo and Dr. R. Avila are Postdoctoral Research Fellows in the Department of Nutrition, Harvard School of Public Health.

\section{References}

1. Fulmer, J. D. 1982. The interstitial lung diseases. Chest. 82:172-178. 
2. Crystal, R. G., J. E. Gadek, V. J. Ferrans, B. R. Line, and G. W. Hunninghake. 1981. Interstitial lung diseases: current concepts of pathogenesis, staging and therapy. Am. J. Med. 70:542-568.

3. Crystal, R. G. 1987. Interstitial lung disorders. In Principles of Internal Medicine. 11 th ed. E. Braunwald et al., editors. McGraw-Hill Book Co., New York. 1095-1 105.

4. Selman, M., M. Montano, C. Ramos, and R. Chapela. 1986 Concentration, biosynthesis and degradation of collagen in idiopathic pulmonary fibrosis. Thorax. 41:355-359.

5. Rennard, S. I., G. W. Hunninghake, P. B. Bitterman, and R. G. Crystal. 1981. Production of fibronectin by the human alveolar macrophage: mechanism for the recruitment of fibroblasts to sites of tissue injury in interstitial lung diseases. Proc. Natl. Acad. Sci. USA. 78:7147-7151.

6. Bitterman, P., B. S. Adelberg, and R. G. Crystal. 1983. Pulmonary fibrosis. Spontaneous release of the alveolar macrophage-derived growth factor in the interstitial lung disorders. J. Clin. Invest. 72:1801-1813.

7. Martinet, Y., P. B. Bitterman, J. Mornex, G. R. Grotendorst, and R. M. Crystal. 1986. Activated human monocytes express the c-sis protooncogene and release a mediator showing PDGF-like activity. Nature (Lond.). 319:158-160.

8. Pantazis, P., E. Sariban, D. Kufe, and H. N. Antoniades. 1986. Induction of c-sis gene expression and synthesis of platelet-derived growth factor in human myeloid leukemia cells during monocytic differentiation. Proc. Natl. Acad. Sci. USA. 83:6455-6459.

9. Antoniades, H. N., and M. W. Hunkapiller. 1983. Human platelet-derived growth factor (PDGF): amino-terminal amino acid sequence. Science (Wash. DC). 220:963-965.

10. Antoniades, H. N., P. Pantazis, and A. J. Owen. 1987. Human platelet-derived growth factor and the sis/PDGF-2 gene. In Oncogenes, Genes, and Growth Factors. G. Guroff, editor. John Wiley \& Sons, Inc., New York. 1-40.

11. Shimokado, K., E. W. Raines, D. K. Madtes, T. B. Barrett, E. P. Benditt, and R. Ross. 1985. A significant part of macrophage-derived growth factor consists of at least two forms of PDGF. Cell. 43:277-286.

12. Mornex, J. F., Y. Martinet, and K. Yamamuchi. 1986. Spontaneous expression of the c-sis gene and release of a platelet-derived growth factorlike molecule by human alveolar macrophages. J. Clin. Invest. 78:61-66.

13. Collins, T., D. Ginsburg, J. M. Boss, S. H. Orkin, and J. S. Pober. 1985. Cultured human endothelial cells express platelet-derived growth factor B-chain: cDNA cloning and structural analysis. Nature (Lond.). 316:748-750.

14. Betsholtz, C., J. Johnsson, C. H. Heldin, B. Westermark, P. Lind, M. S. Urdea, R. Eddy, T. B. Shows, K. Philpott, A. L. Mellor, T. J. Knott, and J. Scott. 1986. cDNA sequence and chromosomal localization of human platelet-derived factor A-chain and its expression in tumor cell lines. Nature (Lond.). 320:695-699.

15. Ponte, P., S.-Y. Ng, J. Engel, P. Cunning, and L. Kedes. 1984. Evolutionary conservation in the untranslated regions of action mRNAs: DNA sequence of a human b-actin cDNA. Nucleic Acids Res. 12:1687-1696.

16. Höffler, H., H. Childers, M. R. Monminy, R. M. Lechan, R. H. Goodman, and Y. J. Wolfe. 1986. In situ hybridization methods for the detection of somatostatin mRNA in tissue sections using antisense RNA probes. Histochem. J. 18:587-594.
17. Gown, A. M., T. Tsukada, and R. Ross. 1986. Human atherosclerosis II. Immunocytochemical analysis of the cellular composition of human atherosclerotic lesions. Am. J. Pathol. 25:191-107.

18. Höffler, H., R. A. DeLellis, and M. J. Wolfe. 1988. In situ hybridization and immunocytochemistry. In Advances in Immunohistochemistry. R. A. DeLellis, editor. Raven Press, New York. 47-66.

19. Martinet, Y., W. N. Rom, G. R. Grotendorst, G. R. Martin, and R. G. Crystal. 1987. Exaggerated spontaneous release of plateletderived growth factor by alveolar macrophages from patients with idiopathic pulmonary fibrosis. N. Engl. J. Med. 317:202-209.

20. Wilcox, J. N., K. M. Smith, L. T. Williams, S. M. Schwartz, and D. Gordon. 1988. Platelet-derived growth factor mRNA detection in human atherosclerotic plaques by in situ hybridization. J. Clin. Invest. 82:1134-1143.

21. Barrett, T. B., C. M. Gajducek, S. M. Schwartz, J. K. Swartz, and E. P. Benditt. 1984. Expression of the sis gene by endothelial cells in culture and in vivo. Proc. Natl. Acad. Sci. USA. 81:6772-6774.

22. Sitaras, N. H., E. Sariban, P. Pantazis, B. Zetter, and H. N. Antoniades. 1987. Human iliac artery endothelial cells express both genes encoding the chains of platelet-derived growth factor (PDGF) and synthesize PDGF-like mitogen. J. Cell Physiol. 132:376-380.

23. Rosengurt, E., J. Sinnet-Smith, and J. Taylor-Papadimitrov. 1985. Production of PDGF-like growth factor by breast cancer cell lines. Int. J. Cancer. 36:247-252.

24. Bronzert, D. A., P. Pantazis, H. N. Antoniades, A. Kasid, N. Davidson, R. B. Dickson, and M. E. Lippman. 1987. Synthesis and secretion of PDGF-like growth factor by human breast cancer cell lines. Proc. Natl. Acad. Sci. USA. 84:5763-5767.

25. Sariban, E., N. M. Sitaras, D. W. Kufe, H. N. Antoniades, and P. Pantazis. 1988. Expression of PDGF-related transcript and synthesis of biologically active PDGF-like proteins by human malignant epithelial cell lines. J. Clin. Invest. 82:1157-1164.

26. Sitaras, N., E. Sariban, M. Bravo, P. Pantazis, and H. N. Antoniades. 1988. Constitutive production of PDGF-like proteins by human prostate carcinoma cell line. Cancer Res. 48:1930-1935.

27. Grotendorst, G. R., H. E. Seppa, H. K. Kleinman, and G. R. Martin. 1981. Attachment of smooth muscle cells to collagen and their migration toward platelet-derived growth factor. Proc. Natl. Acad. Sci. USA. 78:3669-3672.

28. Seppa, H. E., G. R. Grotendorst, S. Seppa, E. Schiffmann, and G. R. Martin. 1982. Platelet-derived growth factor is chemotactic for fibroblasts. J. Cell Biol. 92:584-588.

29. Bernstein, L. R., H. N. Antoniades, and B. R. Zetter. 1982. Migration of cultured vascular cells in response to plasma and platelet-derived growth factor. J. Cell Sci. 56:71-82.

30. Selman, M., M. Montaño, I. Montfort, and R. Perez Tamayo. 1985. A new model of diffuse interstitial pulmonary fibrosis in the rat. Exp. Mol. Pathol. 43:375-387.

31. Greenberg, S. D., R. M. O'Neal, and D. E. Jenkins. 1974. The pathological findings in diffuse interstitial fibrosis of the lungs. South Med. J. 67:571-579.

32. Bauer, E., T. Cooper, J. Huang, J. Altman, and T. Deuel. 1985. Stimulation of in vitro human skin collagenase expression by plateletderived growth factor. Proc. Natl. Acad. Sci. USA. 82:4132-4136.

33. Crystal, R. G., J. D. Fulmer, W. C. Roberts, M. L. Moss, B. R. Line, and H. Y. Reynolds. 1976. Idiopathic pulmonary fibrosis: clinical, histologic, radiographic, physiologic, scintigraphic, cytologic, and biochemical aspects. Ann. Intern. Med. 85:769-788. 